\title{
Coopetition in international maritime shipping
}

\author{
Dung-Ying Lin, Ph.D., Associate Professor \\ Chien-Chih Huang, B. Sc. \\ National Cheng Kung University, Taiwan
}

\begin{abstract}
The increasingly competitive nature of maritime freight transport has stimulated carriers to improve efficiency and lower costs. The industry has gradually matured, and it has recently become the case that the larger a carrier is, the more competitive advantage it has. Therefore, carriers form strategic alliances to collaborate with each other so that they can reduce their operational costs due to economies of scale. At the same time, such alliances allow carriers to improve the quality of their service by increasing their network coverage. Although carriers collaborate to improve their operational efficiency, they compete with each other simultaneously. In other words, a game of coopetition among carriers has developed in international maritime freight transport in recent years. In this study, we propose a theoretical framework for characterizing coopetition in international maritime shipping and investigating how carriers can manage their business models. Empirical studies, together with salient analytical results, are presented and discussed.
\end{abstract}

Keywords: Coopetition; Maritime freight; International shipping; Jacobi approach; Backward induction

\section{INTRODUCTION}

In recent years, fundamental changes have taken place in the operational models of international maritime shipping. Traditionally, carriers assign ships of various sizes to pick up containers along the countries of the Pacific Rim. For instance, as Figure 1 illustrates, a ship of 10,000 TEU or over may depart from Japan and pick up loads from Korea, China, Hong Kong and Singapore and then depart Asia for ports in Europe (e.g., Rotterdam). However, the more ports at which a ship stops, the more delay it may potentially incur. Specifically, the ship has to wait during the berthing, loading and unloading processes. The time required for each of these can vary significantly, depending on the efficiency of the stopping ports. As a result, the number of ports at which a ship stops is directly related to the reliability of the shipping time to which the carrier can commit. To improve the reliability of the service provided, carriers have proposed an alternative operational model of daily frequency. The carrier conceptually considers certain ports in the current network associated with high customer demand as mega-hubs (e.g., Pusan, Shanghai, Hong Kong and Singapore) and dispatches its largest ships to pick up and deliver shipments at those ports. Shipments from smaller ports, such as Tianjin, are carried by feeder ships to the mega-hubs.

The new operational model is very similar to hub-andspoke operation in air transportation and has provided several advantages for maritime freight carriers. First, because the carriers use large ships to service selected major ports, these large ships (e.g., ships over 10,000 TEU) do not need to operate at full speed between mega-hubs because a large ship can cover a given distance more quickly than a small ship can. Therefore, a large ship can increase its speed when the pre-specified schedule is delayed and improve the reliability of the schedule. This gives the carrier the operational flexibility to improve its service quality. Second, if the number of ships is abundant, carriers can provide pickup and delivery services at the megahubs on a daily basis. Presuming that it requires 40 days to travel from the Asian ports to Europe, carriers can provide daily service as long as they have 40 large ships. Thus, a high service frequency greatly improves a carrier's competitive advantage. Third, carriers can achieve economies of scale at the megahubs, in the same way that economies of scale are achieved at hubs in a hub-and-spoke air transport network. Lastly, this new business model has implications for energy consumption and environmental impact because the large ships in the network can operate at slower speeds, thereby consuming less energy and generating less pollution.

In a winner-take-all market, carriers need to develop new strategies in response to this new operational model so that they can survive in the market. With this in mind, carriers have proposed collaboration so that the number of ships and the service network can be expanded. As they adopt the collaboration strategy, they compete with each other at the same time because carriers have to defend their own profits. In such a scenario, a game of coopetition develops. In this study, we investigate the coopetition game and analyze its 


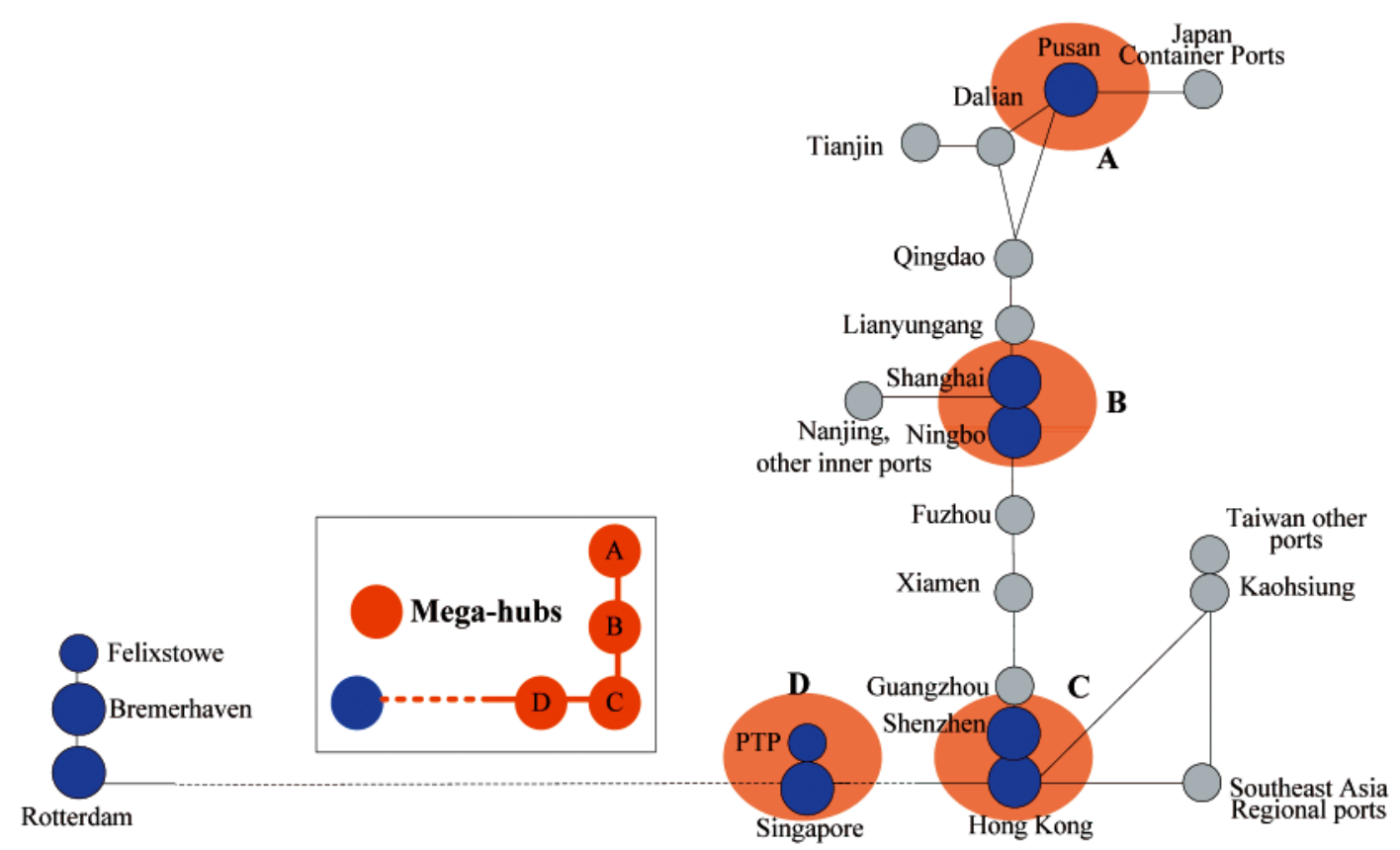

Fig. 1. The new operational model in maritime international shipping (Tai and Lin, 2012)

mathematical properties. Because the game of coopetition is rarely discussed in the literature, we develop its equilibrium condition and solution approach to gain insight into empirical studies of this phenomenon.

The remainder of the paper is structured as follows. Section 2 provides a critical overview of the recent developments in the field of coopetition and maritime freight shipping and related fields of research. Section 3 presents a mathematical model of the coopetition framework. Section 4 presents a proposed solution procedure, a diagonalization algorithm, for finding the solution of the mathematical model described in Section 3. In Section 5, the proposed method is applied empirically to networks with various sets of parameters to demonstrate their efficacy. The final section concludes the paper and suggests potential directions for future research.

\section{LITERATURE REVIEW}

To survive in the challenging and increasingly competitive maritime freight transportation industry, carriers strive to improve their efficiency and lower their costs. To accomplish these goals, carriers need to consider alternative business models such as competition, cooperation and coexistence/coopetition (Bengtsson and Kock, 1999). A considerable amount of research exists in the field of freight cooperation. For instance, Özener and Ergun (2008) studied cost allocation in shipper alliances. Based on previous work on the lane covering problem, Ergun et al. (2007) developed optimization techniques for identifying collaborative shippers' tours to reduce the probability of empty truck repositions. Such carrier collaboration techniques have been applied in areas such as air and sea cargo [e.g., Agarwal et al. (2010), Agarwal and Ergun, (2008) and Houghtalen et al. (2010)]. The aforementioned cooperation research assumed that collaborators work together to find the optimal solution for the collaborative system. Therefore, conventional optimization techniques (rather than a game-theoretic framework) can be applied.

An alternative line of research has applied the gametheoretic framework to analyzing cooperation and competition strategies. We can further classify the related research into cooperative or non-cooperative game theory research. An extensive review of cooperative game-theoretic models can be found in Nagarajan and Sosic (2008). Sutton (1986) provided a critical review of non-cooperative game models. An updated overview of non-cooperative game models can be found in Cachon and Netessine (2004). From the literature summarized above, it is apparent that only a limited body of research has been devoted to the game of players cooperating and competing simultaneously, especially in the field of maritime freight transportation. In international air services, airlines have widely adopted the practice of codesharing that designates its code on aircraft operated by other airlines (Humphreys, 1994). Code-sharing among airlines can supplement their own flight frequencies or establish a new market presence. However, the practice can lower the cost to other airlines and make them more competitive in the industry, which can similarly form a game of coopetition. Further, most of the research in this area focuses on the design of the code-sharing system rather than analyzing the problem from a coopetition game perspective. Luo (2007) explained why coopetition occurs, developed an overall framework to analyze coopetition and presented a typology for understanding the intensity and diversity of coopetition with major global rivals. However, this research is more a conceptual effort than a mathematical or theoretical analysis of coopetition. To the best of our knowledge, the work by Ngo and Okura (2008) is the first of the very few research efforts that have been devoted explicitly to the mathematics of the coopetition game. However, their models, which focused on the coopetition game between a semipublic firm and a private firm in a duopoly market, cannot be applied in the analysis of the coopetition games between private freight carriers in maritime transportation. Therefore, in this research, we develop the theoretical background of the coopetition game in a duopoly market so that the competition and cooperation between maritime freight carriers can be captured with greater fidelity. We next present the mathematical model.

\section{COOPETITION MODEL}

In this section, we present the mathematical model for the coopetition game. Before presenting the mathematical derivation, we first state the following assumptions on which the model is based: 
1. The game of two carriers. For simplicity, we consider a game structure with two freight carriers in an oligopoly market. The assumption is not meant to be restrictive but to facilitate explanation of the derivation process. One can easily expand the derivation and algorithm to more than two players in the game.

2. Carriers are equally competitive. We assume that there is no leader or follower in this game. Two separate carriers in a duopoly freight transport market offer partially substitutive freight service.

3. An extensive-form game. An extensive-form game is a specification of a game in game theory that allows explicit representation of a number of important aspects, such as the sequencing of players' possible moves, their choices at every decision point, the information each player has about the other player's moves when she/he makes a decision, and the payoffs for all possible game outcomes.

4. A two-stage game. We consider a typical sequential game with two stages. In the first stage, freight carriers cooperate to decrease the average cost and increase the total market profit. In the second stage, carriers simultaneously choose their competitive effort level to increase the carrier's own market share. This is the common setup for analyzing this stream of problems.

5. Perfect information. Two carriers are assumed to have perfect information in cooperate investment and price competition strategies of the market.

6. Static game. We do not consider the dynamic features of this game and assume that carriers' decisions do not vary over time.

We next introduce the notations that will be used throughout the rest of the paper.

\section{Notations}

$\mathrm{y}_{1}$

- The cooperative effort level of each carrier $i, i \in$ $\{1,2\}$ that decreases the average cost and increases the total market size.

$\mathrm{x}_{\mathrm{i}}-$ The competitive level of each carrier $\mathrm{i}, \mathrm{i} \in\{1,2\}$ that can enhance a carrier's own market share

$\mathrm{s}_{\mathrm{i}} \quad-$ The market share of carrier $\mathrm{i}, \mathrm{i} \in\{1,2\}$. The value of $s_{i}$ is determined by each carrier's competitive level. For instance, $\mathrm{s}_{\mathrm{i}}=\mathrm{x}_{\mathrm{i}} / \mathrm{x}_{\mathrm{i}}+\mathrm{x}_{\mathrm{j}}$ if $\mathrm{i}$ and $\mathrm{j}$ represent the two carriers in the market.

$c\left(y_{1}, y_{2}\right)-$ The average cost for each carrier, which is a function of $\mathrm{y}_{1}$ and $\mathrm{y}_{2}$.

$\mathrm{q}\left(\mathrm{y}_{1}, \mathrm{y}_{2}\right)-$ The total market demand, which is a function of $\mathrm{y}_{1}$ and $\mathrm{y}_{2}$.

$\mathrm{p}(\mathrm{q}) \quad-$ The equilibrium market price, which is a function of market demand.

D $\quad-$ The initial demand before the game.

$\mathrm{k}_{\mathrm{x}} \quad-$ The unit cost of increasing one unit of competitive level.

$\mathrm{k}_{\mathrm{y}} \quad-$ The unit cost of increasing one unit of cooperative level.

$\mathrm{k}_{\mathrm{x}}, \mathrm{x}_{\mathrm{i}} \quad-$ The cost of expanding competitive efforts for each carrier $i, i \in\{1,2\}$

$\mathrm{k}_{\mathrm{y}}, \mathrm{y}_{\mathrm{i}}^{2} \quad-$ The cost of cooperative efforts for each carrier $\mathrm{i}, \mathrm{i} \in$ $\{1,2\}$. Note that $y_{i}^{2}$ is a mathematical construct that makes the derivation easier when calculating $y_{i}{ }^{*}$ at a later stage. One can alter this functional form and obtain similar results rather straightforwardly.

\section{Backward induction}

To derive the equilibrium condition of this coopetition game, we use the method of backward induction (McCain,
2010). The concept of backward induction is based on the game-theoretic principle of "think forward and reason backward," which is similar to the techniques used in solving a dynamic programming problem. The primary difference is that there typically exists only one decision maker in a dynamic program problem, while there are generally two or more players interacting in the context of a game. Essentially, the backward induction reasons backwards in time from the end of a game to determine a sequence of optimal decisions along the sequential process. It proceeds by first considering the last time a decision can be made and then choosing what to do in any situation at that time. Based on the results, game players can then determine what to do at the previous step at the time to make a decision. This process continues backwards until the best action for every possible scenario at every decision point in time has been determined. We next apply the backward induction technique in deriving the equilibrium condition.

\section{Derivation of Equilibrium Condition}

We first assume that the total demand of two freight carriers depends on the level of cooperation in the two-stage game. In this static game, both carriers choose their cooperative effort levels to increase total market size in the first stage. In the second stage, carriers choose their competitive levels to increase their corresponding market shares. Therefore, the overall market demand function can be expressed as follows:

$$
\mathrm{q}\left(\mathrm{y}_{1}, \mathrm{y}_{2}\right)=\mathfrak{D}+\mathrm{y}_{1}+\mathrm{y}_{2}
$$

The form of this demand function is based on the work by Ngo and Okura (2008) and can be modified to suit various situations. For readability, we replaced $\mathrm{q}\left(\mathrm{y}_{1}, \mathrm{y}_{2}\right), \mathrm{c}\left(\mathrm{y}_{1}, \mathrm{y}_{2}\right)$ and $\mathrm{p}$ with $\mathrm{Q}, \mathrm{C}$ and $\mathrm{P}$ so that the derivation process is clearer. The utility/profit functions of carrier 1 and 2 are:

$$
\begin{aligned}
& \pi_{1}=(\mathrm{P}-\mathrm{C}) \mathrm{Qs}_{1}-\mathrm{k}_{\mathrm{x}} \mathrm{x}_{1}-\mathrm{k}_{\mathrm{y}} \mathrm{y}_{1}{ }^{2} \\
& \pi_{2}=(\mathrm{P}-\mathrm{C}) \mathrm{Qs}_{2}-\mathrm{k}_{\mathrm{x}} \mathrm{x}_{2}-\mathrm{k}_{\mathrm{y}} \mathrm{y}_{2}{ }^{2}
\end{aligned}
$$

Again, the functional forms are based on Ngo and Okura (2008) and can be modified if necessary. To make the model reasonable, without loss of generality, we impose the following constraints:

$$
\begin{gathered}
\mathrm{P} \geq \mathrm{C} \geq 0 \\
\mathrm{x}_{1} \geq 0, \mathrm{x}_{2} \geq 0 \\
\mathrm{y}_{1} \geq 0, \mathrm{y}_{2} \geq 0
\end{gathered}
$$

$\mathrm{P} \geq \mathrm{C} \geq 0$ implies that the price of the service is higher than its cost and should naturally have a positive value. Similarly, the competition levels $\mathrm{x}_{1}$ and $\mathrm{x}_{2}$ and the cooperation levels $\mathrm{y}_{1}$ and $y_{2}$ should be greater than zero. As mentioned earlier, to derive the solution of this extensive-form game, we solve the game by backward induction. That is, the equilibrium in the second stage is derived on the basis of the first stage before the first stage has been played. Having derived the equilibrium condition in the second stage, the equilibrium condition in the first stage is derived using the results from the second stage. The second stage of the game is described below. The first-order conditions with respect to $\mathrm{x}_{\mathrm{i}}$ required to obtain the corresponding maximum utilities are:

$$
\begin{aligned}
& \frac{\partial \pi_{1}}{\partial x_{1}}=\frac{x_{2} Q(P-C)}{\left(x_{1}+x_{2}\right)^{2}}-k_{x}=0 \\
& \frac{\partial \pi_{2}}{\partial x_{2}}=\frac{x_{1} Q(P-C)}{\left(x_{1}+x_{2}\right)^{2}}-k_{x}=0
\end{aligned}
$$


The cost of expanding the competitive effort for each carrier therefore are:

$$
\mathrm{k}_{\mathrm{x}} \mathrm{x}_{1}^{*}=\mathrm{k}_{\mathrm{x}} \mathrm{x}_{2}^{*}=\frac{\mathrm{Q}(\mathrm{P}-\mathrm{C})}{4}
$$

We can conclude that the equilibrium competitive effort levels are:

$$
\mathrm{x}_{1}^{*}=\mathrm{x}_{2}^{*}=\frac{\mathrm{Q}(\mathrm{P}-\mathrm{C})}{4 \mathrm{k}_{\mathrm{x}}}
$$

Because an increase in $\mathrm{k}_{\mathrm{x}}$ decreases $\mathrm{x}_{1}{ }^{*}$ and $\mathrm{x}_{2}{ }^{*}$, the intuitive interpretation is that the higher the cost level, the lower the competitive effort. Next, we consider the relationship between competitive and cooperative effort levels. From equation (7) the following derivatives can be calculated:

$$
\begin{aligned}
& \frac{\partial \mathrm{x}_{1}}{\partial \mathrm{y}_{1}}=\frac{\partial \mathrm{x}_{2}}{\partial \mathrm{y}_{1}}=\frac{\mathrm{P}\left(1+\frac{1}{\mathrm{~s}_{\mathrm{d}}}\right)-\mathrm{C}\left(1+\frac{1}{\mathrm{~s}_{\mathrm{c}}}\right)}{4 \mathrm{k}_{\mathrm{x}}} \\
& \frac{\partial \mathrm{x}_{2}}{\partial \mathrm{y}_{2}}=\frac{\partial \mathrm{x}_{1}}{\partial \mathrm{y}_{2}}=\frac{\mathrm{P}\left(1+\frac{1}{\mathrm{~s}_{\mathrm{d}}}\right)-\mathrm{C}\left(1+\frac{1}{\mathrm{~s}_{\mathrm{c}}}\right)}{4 \mathrm{k}_{\mathrm{x}}}
\end{aligned}
$$

When $\mathrm{P}\left(1+\frac{1}{\mathrm{~S}_{\mathrm{d}}}\right)-\mathrm{C}\left(1+\frac{1}{\mathrm{~S}_{\mathrm{c}}}\right)<0$, the competitive level decreases when the cooperative level increases. We can conclude that $\mathrm{x}_{\mathrm{i}}$ and $\mathrm{y}_{\mathrm{i}}$ are substitutes.

On the other hand, when $\mathrm{P}\left(1+\frac{1}{\mathrm{~S}_{\mathrm{d}}}\right)-\mathrm{C}\left(1+\frac{1}{\mathrm{~S}_{\mathrm{c}}}\right)>0$, the competitive level increases when the cooperative level increases. Thus, we can observe that $\mathrm{x}_{\mathrm{i}}$ and $\mathrm{y}_{\mathrm{i}}$ are complements.

We next use backward induction to analyze the first stage of the game from the results of second stage. Plugging $\mathrm{x}_{1}{ }^{*}$ and $\mathrm{x}_{2}{ }^{*}$ into the carriers' utility functions leads to:

$$
\begin{aligned}
& \pi_{1}=\frac{\mathrm{Q}(\mathrm{P}-\mathrm{C})}{4}-\mathrm{k}_{\mathrm{y}} \mathrm{y}_{1}^{2} \\
& \pi_{2}=\frac{\mathrm{Q}(\mathrm{P}-\mathrm{C})}{4}-\mathrm{k}_{\mathrm{y}} \mathrm{y}_{2}^{2}
\end{aligned}
$$

Applying the condition that $\partial \pi_{\mathrm{i}} / \partial \mathrm{y}_{\mathrm{i}}=0, \forall \mathrm{i} \in\{1,2\}$, the equilibrium cooperative effort levels are:

$$
\mathrm{y}_{1}^{*}=\mathrm{y}_{2}^{*}=\frac{\mathrm{P}\left(1+\frac{1}{\mathrm{~s}_{\mathrm{d}}}\right)-\mathrm{C}\left(1+\frac{1}{\mathrm{~s}_{\mathrm{c}}}\right)}{8 \mathrm{k}_{\mathrm{y}}}
$$

To summarize the results and replace the notations with the original meanings, we list the following equilibrium condition for this coopetition game:

$$
\begin{gathered}
\mathrm{x}_{1}^{*}=\mathrm{x}_{2}^{*}=\frac{\mathrm{q}\left(\mathrm{y}_{1}, \mathrm{y}_{2}\right)\left\{\mathrm{p}(\mathrm{q})-\mathrm{c}\left(\mathrm{y}_{1}, \mathrm{y}_{2}\right)\right\}}{4 \mathrm{k}_{\mathrm{x}}} \\
\mathrm{y}_{1}^{*}=\mathrm{y}_{2}^{*}=\frac{\mathrm{p}(\mathrm{q})\left(1+\frac{1}{\mathrm{~s}_{\mathrm{c}}}\right)-\mathrm{c}\left(\mathrm{y}_{1}, \mathrm{y}_{2}\right)\left(1+\frac{1}{\mathrm{~s}_{\mathrm{c}}}\right)}{8 \mathrm{k}_{\mathrm{y}}}
\end{gathered}
$$

From equations (13) and (14) we can observe that the equilibrium cooperative and competitive levels are identical for both carriers, which suggests that carriers will adopt the same strategies in this coopetition game when reaching equilibrium and the result profits would be identical as well. Therefore, we only present the cooperation, competition and profit levels of a carrier in the section of numerical studies. Next, we present a theorem stating that there exists a unique solution to this coopetition game.

\section{Theorem 1}

There exists a unique solution to the game-theoretic model of the coopetition.

Proof. See the Appendix I..

As mentioned earlier, we consider a game structure with two freight carriers in an oligopoly market to facilitate explanation of the derivation process. However, the assumption is not meant to be restrictive. The extension of the derivation to three carriers is presented in Appendix II. For the cases with more than three carriers, the derivation can be expanded in the same manner.

\section{SOLUTION APPROACH: DIAGONALIZATION (JACOBI) ALGORITHM}

The iterative diagonalization algorithm by Lin and Hsieh (2012) can be applied to evaluate the model empirically. The fundamental objective of this algorithm is to determine the optimal collaboration and competition efforts of one carrier while assuming that the efforts of other carriers are known and fixed. Given the optimal values for the current carrier, one can then calculate the optimal efforts of the other carriers for the same set of conditions (the values for other carriers are fixed and known). The process repeats iteratively until a prespecified criterion is satisfied and converges to an equilibrium solution. The typical convergence criterion is that the difference of two consecutive solutions be within a tolerant value. The algorithmic steps can be described as follows:

Step 0: Initialization

We initialize the following parameters required for the algorithms, including the iteration number $n$, the cost of cooperation $\mathrm{k}_{\mathrm{y}}$, the cost of competition $\mathrm{k}_{\mathrm{x}}$ and the initial demand before the game starts $\mathfrak{D}$. Furthermore, we assume that the carriers in this game do not cooperate before the game. In other words, the cooperation level $\mathrm{y}_{\mathrm{i}}^{\mathrm{n}}=0, \forall \mathrm{i} \in \mathrm{I}$.

Step 1: Diagonalization

At iteration n, we solve the equilibrium coopetition level, equations (13) and (14) for carrier $i \in I$, by assuming the competition and cooperation levels for other carriers $j \in I \backslash i$ are given and unchanged from the previous iteration $n-1$. This is equivalent to solving the equilibrium problem (equations (13) and (14)) with the diagonal elements of a Jacobian matrix of coopetition levels, which determines the competition and cooperation levels of carrier $i \in \mathrm{I}$.

Step 2: Convergence Test

If the cooperation level of a firm $y_{i}{ }^{n}$ between two consecutive iterations is less than a pre-specified level $\left(\mathrm{y}_{i}{ }^{\mathrm{n}}\right.$ $\left.-\mathrm{y}_{\mathrm{i}}^{\mathrm{n}-1}\right) / \mathrm{y}_{\mathrm{i}}^{\mathrm{n}} \leq 5 \%$, report the incumbent solution. Otherwise, $\mathrm{n}=\mathrm{n}+1$; go back to Step 1 .

Note that when cooperation level $\mathrm{y}_{i}{ }^{\mathrm{n}}$ reaches an equilibrium condition, $\mathrm{x}_{\mathrm{i}}$ stops changing as well. Thus, $\mathrm{y}_{\mathrm{i}}{ }^{\mathrm{n}}$ can be used as the convergence criterion. We next show the convergence of the diagonalization algorithm.

\section{Theorem 2}

The diagonalization algorithm converges to a unique solution of this coopetition game.

Proof. Because the profit function of each carrier is concave (shown in Theorem 1), the gradient (marginal profit function) is monotonic. For a problem with such an objective function, Dafermos (1983) established that the diagonalization algorithm converges to a unique solution..

In addition to the convergence behavior established by Dafermos (1983), the convergence of the diagonalization 
algorithm can be interpreted in a more intuitive manner. Let us use the competitive level $\mathrm{x}_{\mathrm{i}}$ as an example. As the diagonalization algorithm solve the coopetition game iteratively, the competitive level in iteration $\mathrm{n}+2\left(\mathrm{x}_{\mathrm{i}}{ }^{\mathrm{n}+2}\right)$ can only be lower than the competitive level in iteration $n\left(x_{i}{ }^{n}\right)$. Note that $\mathrm{x}_{\mathrm{i}}^{\mathrm{n}+2}$ essentially uses the competitive level $\mathrm{x}_{\mathrm{i}}^{\mathrm{n}}$ as the initial level and the value of $x_{i}{ }^{n+2}$ involves one step of cooperative effort based on $x_{i}^{n}$. Therefore, $x_{i}^{n+2}$ is always smaller than $x_{i}^{n}$ because the competition level can only be smaller if one step of cooperation is involved. Therefore the convergence of the diagonalization can be expected.

\section{NUMERICAL EXPERIMENTS}

For the numerical studies, we assume that there are two carriers in the market and that the carriers are in a duopoly market with a linear demand function $\mathrm{q}=100-\mathrm{p}$ and $\mathrm{q}=90-\mathrm{c}$. It is worth noting that, given the above two functions, we make the assumption that the carrier makes a profit with a value of 10 if it sells one unit of its product $(\mathrm{p}-\mathrm{c}=10)$. Finally, equation (1) is of the form $q=5+y_{1}+y_{2}$. The functional form of this equation $\left(\mathrm{q}\left(\mathrm{y}_{1}, \mathrm{y}_{2}\right)=\mathfrak{D}+\mathrm{y}_{1}+\mathrm{y}_{2}\right)$ is based on the work by Ngo and Okura (2008). Thus the initial demand (D) is 5 . The unit cost of increasing one unit of competitive level $\left(\mathrm{k}_{\mathrm{x}}\right)$ and cooperative level $\left(\mathrm{k}_{\mathrm{y}}\right)$ are 5 and 1 respectively. Using this set of randomly chosen data, we find the equilibrium competition level to be 3.75 units and the cooperation level to be 1.25 units. The resulting profit is 17.5 units. It is worth noting that this value reflects only the magnitude of the efforts that the carriers devote to cooperation and competition. For instance, each carrier decides to devote $75 \%$ to competing and $25 \%$ to cooperating. To further validate the model's correctness and reasonableness, we present sensitivity analyses of parameters in the following sections.

\subsection{Sensitivity analysis of initial demand level}

We next perturb the parameters so that we can observe their impact. We first vary the initial demand level $\mathfrak{D}$ in equation (1) $\left(\mathrm{q}\left(\mathrm{y}_{1}, \mathrm{y}_{2}\right)=\mathfrak{D}+\mathrm{y}_{1}+\mathrm{y}_{2}\right)$ and summarize the impact of this value on the equilibrium results in Table 1 .

We can see from Table 1 that the competition level increases and the cooperation level remains constant as the initial demand level $\mathfrak{D}$ increases. From equations (13) and (14), we can observe consistent results. As the initial demand level increases, carriers compete more to increase their own market shares and their cooperation levels do not vary with initial demand. However, with the rising initial demand, both carriers gain more profit.

Tab. 1. Sensitivity Analysis of Initial Demand Level

\begin{tabular}{|c|c|c|c|}
\hline $\mathfrak{D}$ & $\begin{array}{c}\mathbf{x}^{*} \\
\text { (competition level) }\end{array}$ & $\begin{array}{c}\mathbf{y}^{*} \\
\text { (cooperation level) }\end{array}$ & $\begin{array}{c}\text { П } \\
\text { (profit) }\end{array}$ \\
\hline 5 & 3.75 & 1.25 & 17.50 \\
\hline 10 & 6.25 & 1.25 & 30.00 \\
\hline 15 & 8.75 & 1.25 & 42.50 \\
\hline 20 & 11.25 & 1.25 & 55.00 \\
\hline 25 & 13.75 & 1.25 & 67.50 \\
\hline 30 & 16.25 & 1.25 & 80.00 \\
\hline 35 & 18.75 & 1.25 & 92.50 \\
\hline 40 & 21.25 & 1.25 & 105.00 \\
\hline 45 & 23.75 & 1.25 & 117.50 \\
\hline 50 & 26.25 & 1.25 & 130.00 \\
\hline
\end{tabular}

\subsection{Sensitivity analysis of cost of competition}

As the cost of competition increases, the competition level decreases and the cooperation level remains constant, as shown in Figure 2. In other words, the competition cost only has an impact on the competition level x. However, as equation (14) shows, the competition level does not influence the cooperation level y. Therefore, the cooperation level remains the same even if the competition cost is perturbed. One of the interesting phenomena we observe is that the resulting profits of both carriers are identical even for different competition costs. We believe that carriers adjust their competition strategies in response to changes in the competition cost and can there by achieve the same profit level even when the competition cost varies.

\subsection{Sensitivity analysis of cost of cooperation}

In this experiment, we perturb the cost of cooperation and summarize the results in Figure 3.

Unlike the competition cost, which has an impact only on the competition level, an increase in the cooperation cost $\left(\mathrm{k}_{\mathrm{y}}\right)$ decreases both the competition and cooperation levels. We can interpret these results on the basis of equations (13)

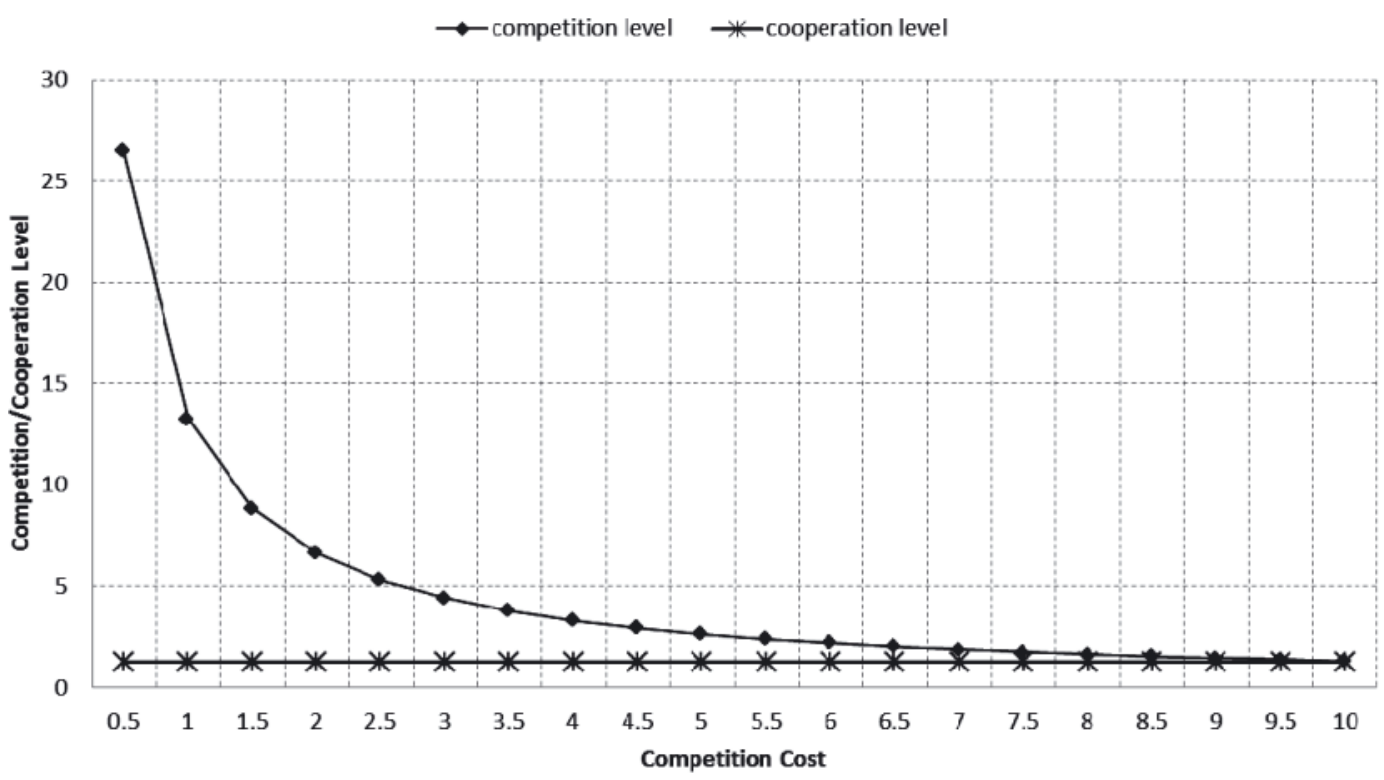

Fig. 2. Sensitivity Analysis of Competition Cost 


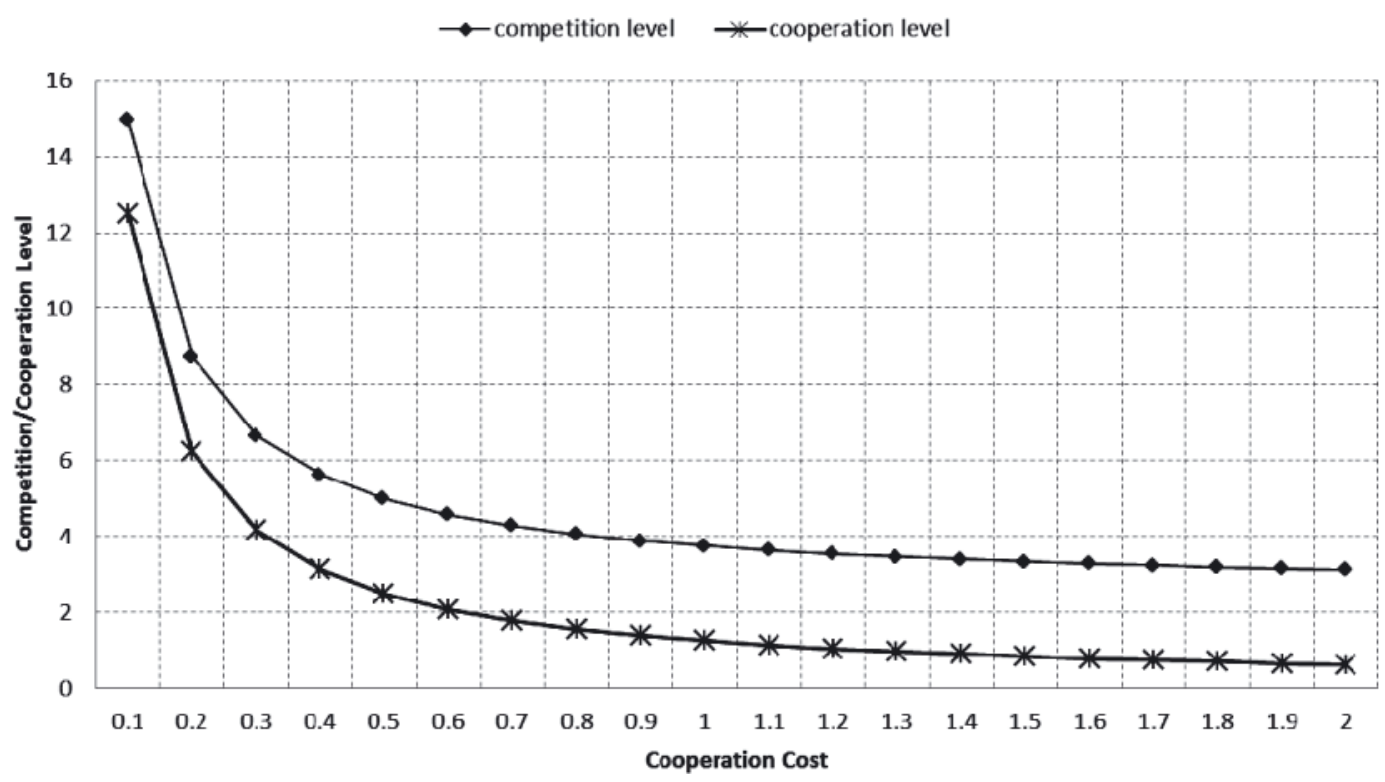

Fig. 3. Sensitivity Analysis of Cooperation Cost

and (14). According to equation (14), a change in the value of $\mathrm{k}_{\mathrm{y}}$ changes the equilibrium cooperation levels $\left(\mathrm{y}_{1}{ }^{*}\right.$ and $\left.\mathrm{y}_{2}{ }^{*}\right)$. Changes in $\mathrm{y}_{1}{ }^{*}$ and $\mathrm{y}_{2}{ }^{*}$ then influence $\mathrm{q}\left(\mathrm{y}_{1}, \mathrm{y}_{2}\right)$ and $\mathrm{c}\left(\mathrm{y}_{1}, \mathrm{y}_{2}\right)$, which results in changes in competition levels. It seems that the cooperation cost has a greater impact on the cooperation level than on the competition level.

\subsection{Sensitivity analysis of parameters in demand function}

Finally, we vary the parameters in the demand function and see how the equilibrium competition and cooperation levels change in response. The results are summarized in Table 2.

Tab. 2. Sensitivity Analysis of Parameters in the Demand Function

\begin{tabular}{|c|c|c|c|c|}
\hline $\boldsymbol{\alpha}$ & $\begin{array}{c}\mathbf{x}^{*} \\
\text { (competition } \\
\text { level) }\end{array}$ & $\begin{array}{c}\mathbf{y}^{*} \\
\text { (cooperation } \\
\text { level) }\end{array}$ & $\begin{array}{c}\boldsymbol{\pi} \\
\text { (profit) }\end{array}$ & $\begin{array}{c}\boldsymbol{\varepsilon}_{\mathbf{d}} \\
\text { (elasticity) }\end{array}$ \\
\hline 1 & 3.75 & 1.25 & 17.5 & -12.3333 \\
\hline 1.1 & 3.316327 & 1.071429 & 15.51021 & -11.7273 \\
\hline 1.2 & 2.944215 & 0.909091 & 13.81198 & -11.2222 \\
\hline 1.3 & 2.622874 & 0.76087 & 12.3535 & -10.7949 \\
\hline 1.4 & 2.34375 & 0.625 & 11.09375 & -10.4286 \\
\hline 1.5 & 2.1 & 0.5 & 10 & -10.1111 \\
\hline
\end{tabular}

Essentially, as the value of $\alpha$ increases, shippers' or customers' demand levels become less sensitive to price. In other words, the elasticity of price $\left(\varepsilon_{\mathrm{d}}\right)$ decreases as $\alpha$ increases. In this scenario, carriers are less willing to cooperate (the value of $\mathrm{y}^{*}$ decreases) because cooperation will not change the market size much and because carriers have less incentive to cooperate. At the same time, as carriers decrease their competition level, the resulting profit decreases.

\section{CONCLUSION REMARKS}

As the maritime freight transportation industry has become increasingly competitive in recent years, carriers have attempted to create more value by changing their business strategies to improve their operational efficiency, decrease their overall costs and increase business profits. One such strategy is coopetition between carriers in which small carriers collaborate with each other so that they can compete with leading carriers. In such a collaboration, small carriers have to collaborate with and compete with each other at the same time so that they can survive in the business. In this study, this carrier coopetition problem is investigated, and the manner in which a carrier determines its cooperation and competition levels is analyzed. The problem is formulated as a two-stage sequential game and empirically applied to example freight networks. The numerical results provide evidence that the model presented can effectively capture the problem and can be a useful tool in analyzing this type of coopetition game.

Although the numerical tests conducted in this study are limited, some interesting conclusions were drawn and insights gained and are presented in the numerical section. However, this study is not without its limitations. For instance, we assume that carriers in this game are equally competent and have identical capacities. In a more realistic scenario, carriers would be differentiated based on their capacities, and the resulting game might be different. Future research can explore possibilities along this line. Further, this study only observes certain impact of related issues (e.g. operation cost) on cooperation level and competition level empirically. Analytical analyses of these issues on the level of cooperation or competition should be explored. Finally, the current research assumes that there are not bargaining power differences among carriers. Including the bargaining power that differs based on carrier size or other factors can be an interesting research topic.

Appendix I: Proof of Solution Uniqueness of the Profit Maximization Program

To prove the uniqueness of the solution of this game-theoretic coopetition model, we need to prove that the program is concave. Because the constraints introduced in the model are of linear form ( $P \geq C \geq 0, x_{1} \geq 0, x_{2} \geq 0, y_{1} \geq 0, y_{2} \geq 0$ ), we only need to show that the objective function is concave for the whole program to be concave.

Denoting $\pi_{\mathrm{i}}=(\mathrm{P}-\mathrm{C}) \mathrm{Q} \mathrm{s}_{\mathrm{i}}-\mathrm{k}_{\mathrm{x}} \mathrm{x}_{\mathrm{i}}-\mathrm{k}_{\mathrm{y}} \mathrm{y}_{\mathrm{i}}^{2}, \mathrm{i} \in\{1,2\}$ as function $\mathrm{f}\{$.$\} , we need to show that \mathrm{f}\left[\theta\left(\mathrm{x}_{\mathrm{i}}^{1}, \mathrm{y}_{\mathrm{i}}^{1}\right),(1-\theta)\left(\mathrm{x}_{\mathrm{i}}^{2}, \mathrm{y}_{\mathrm{i}}{ }^{2}\right)\right] \geq \theta \mathrm{f}\left(\mathrm{x}_{\mathrm{i}}^{1}, \mathrm{y}_{\mathrm{i}}{ }^{1}\right)+$ $+(1-\theta) f\left(x_{i}^{2}, y_{i}^{2}\right)$ to reach the desired conclusion. The function inequality can alternatively be denoted as follows: 


$$
\left.\mathrm{f}\left(\theta \mathrm{x}_{1}{ }^{1}, \theta \mathrm{y}_{1}{ }^{1}\right),(1-\theta) \mathrm{x}_{1}^{2},(1-\theta) \mathrm{y}_{1}^{2}\right) \geq \theta \mathrm{f}\left(\mathrm{x}_{1}{ }^{1}, \mathrm{y}_{1}{ }^{1}\right)+(1-\theta) \mathrm{f}\left(\mathrm{x}_{1}^{2}, \mathrm{y}_{1}^{2}\right)
$$

Let $\mathrm{x}_{\mathrm{B}}$ and $\mathrm{y}_{\mathrm{B}}$ be the competition and cooperation levels, respectively, of the other carrier.

The left-hand side of inequality (A1) is:

$$
\begin{gathered}
\left.\mathrm{f}\left(\theta \mathrm{x}_{1}{ }^{1}, \theta \mathrm{y}_{1}{ }^{1}\right),(1-\theta) \mathrm{x}_{1}^{2},(1-\theta) \mathrm{y}_{1}^{2}\right)=(\mathrm{P}-\mathrm{C})\left[\mathfrak{D}+\theta \mathrm{y}_{1}{ }^{1}+(1-\theta) \mathrm{y}_{1}{ }^{2}+\mathrm{y}_{\mathrm{B}}\right] \cdot \frac{\theta \mathrm{x}_{1}^{1}+(1-\theta) \mathrm{x}_{1}^{2}}{\theta \mathrm{x}_{1}^{1}+(1-\theta) \mathrm{x}_{1}^{2}+\mathrm{x}_{\mathrm{B}}}+ \\
-\mathrm{k}_{\mathrm{x}}\left[\theta \mathrm{x}_{1}{ }^{1}+(1-\theta) \mathrm{x}_{1}{ }^{2}\right]-\mathrm{k}_{\mathrm{y}}\left[\theta \mathrm{y}_{1}{ }^{1}+(1-\theta) \mathrm{y}_{1}{ }^{2}\right]^{2}
\end{gathered}
$$

The right-handside of inequality (A1) is:

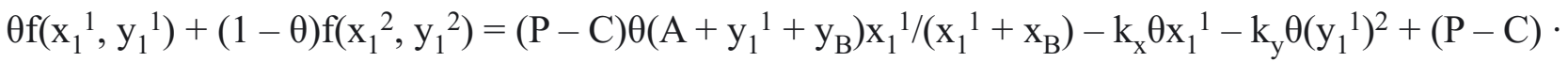

$$
\begin{aligned}
& \cdot(1-\theta)\left(A+y_{1}^{2}+y_{B}\right) x_{1}^{2} /\left(x_{1}^{2}+x_{B}\right)-k_{x}(1-\theta) x_{1}^{2}-k_{y}(1-\theta)\left(y_{1}^{2}\right)^{2}
\end{aligned}
$$

Rearranging the inequality, we obtain the following inequality:

$$
\begin{aligned}
& (\mathrm{P}-\mathrm{C})\left[\mathfrak{D}+\theta \mathrm{y}_{1}{ }^{1}+(1-\theta) \mathrm{y}_{1}{ }^{2}+\mathrm{y}_{\mathrm{B}}\right] \frac{\theta \mathrm{x}_{1}^{1}+(1-\theta) \mathrm{x}_{1}^{2}}{\theta \mathrm{x}_{1}^{1}+(1-\theta) \mathrm{x}_{1}^{2}+\mathrm{x}_{\mathrm{B}}}+\mathrm{k}_{\mathrm{y}}\left[\theta(1-\theta)\left(\mathrm{y}_{1}{ }^{1}-\mathrm{y}_{1}{ }^{2}\right)^{2} \geq\right. \\
& \geq(\mathrm{P}-\mathrm{C}) \theta\left(\mathfrak{D}+\mathrm{y}_{1}{ }^{1}+\mathrm{y}_{\mathrm{B}}\right) \mathrm{x}_{1}{ }^{1} /\left(\mathrm{x}_{1}{ }^{1}+\mathrm{x}_{\mathrm{B}}\right)+(\mathrm{P}-\mathrm{C})(1-\theta)\left(\mathfrak{D}+\mathrm{y}_{1}{ }^{2}+\mathrm{y}_{\mathrm{B}}\right) \mathrm{x}_{1}{ }^{2} /\left(\mathrm{x}_{1}{ }^{2}+\mathrm{x}_{\mathrm{B}}\right)
\end{aligned}
$$

We next simplify the inequality and obtain the following:

$$
\begin{gathered}
\frac{\left\{\theta(1-\theta) \mathrm{x}_{\mathrm{B}}\left(\mathrm{x}_{1}^{1}-\mathrm{x}_{1}^{2}\right)\left[\mathrm{y}_{1}^{2}\left(\mathrm{x}_{1}^{1}+\mathrm{x}_{\mathrm{B}}\right)-\mathrm{y}_{1}^{1}\left(\mathrm{x}_{1}^{2}+\mathrm{x}_{\mathrm{B}}\right)\right]+\theta(1-\theta) \mathrm{x}_{\mathrm{B}}\left(\mathfrak{D}+\mathrm{y}_{\mathrm{B}}\right)\left(\mathrm{x}_{1}^{1}-\mathrm{x}_{1}^{2}\right)^{2}\right\}(P-C)}{\left(\mathrm{x}_{1}^{1}+\mathrm{x}_{\mathrm{B}}\right)\left(\mathrm{x}_{1}^{2}+\mathrm{x}_{\mathrm{B}}\right)\left[\theta \mathrm{x}_{1}^{1}+(1-\theta) \mathrm{x}_{1}^{2}+\mathrm{x}_{\mathrm{B}}\right]}+ \\
+\mathrm{k}_{\mathrm{y}}\left[\theta(1-\theta)\left(\mathrm{y}_{1}^{1}-\mathrm{y}_{1}^{2}\right)^{2}\right] \geq 0
\end{gathered}
$$

Note that, given the assumptions of this model, $\left(\mathrm{x}_{1}{ }^{1}+\mathrm{x}_{\mathrm{B}}\right)\left(\mathrm{x}_{1}{ }^{2}+\mathrm{x}_{\mathrm{B}}\right)\left[\theta \mathrm{x}_{1}{ }^{1}+(1-\theta) \mathrm{x}_{1}{ }^{2}+\mathrm{x}_{\mathrm{B}}\right] \geq 0, \theta(1-\theta) \mathrm{x}_{\mathrm{B}}\left(\mathscr{D}+\mathrm{y}_{\mathrm{B}}\right)\left(\mathrm{x}_{1}{ }^{1}-\mathrm{x}_{1}{ }^{2}\right)^{2} \geq 0$ and $(P-C) \geq 0$. Therefore, we only need to show that $\theta(1-\theta) \mathrm{x}_{\mathrm{B}}\left(\mathrm{x}_{1}{ }^{1}-\mathrm{x}_{1}{ }^{2}\right)\left[\mathrm{y}_{1}{ }^{2}\left(\mathrm{x}_{1}{ }^{1}+\mathrm{x}_{\mathrm{B}}\right)-\mathrm{y}_{1}{ }^{1}\left(\mathrm{x}_{1}{ }^{2}+\mathrm{x}_{\mathrm{B}}\right)\right] \geq 0$ and $(\mathrm{P}-\mathrm{C}) \geq 0$ for the inequality to hold. Note that the conditions $\mathrm{x}_{1}{ }^{1} \geq \mathrm{x}_{1}{ }^{2}, \mathrm{y}_{1}{ }^{1} \leq \mathrm{y}_{1}{ }^{2}$ and $\mathrm{x}_{1}{ }^{1} \leq \mathrm{x}_{1}{ }^{2}, \mathrm{y}_{1}{ }^{1} \geq \mathrm{y}_{1}{ }^{2}$ will ensure that $\theta(1-\theta) \mathrm{x}_{\mathrm{B}}\left(\mathrm{x}_{1}{ }^{1}-\mathrm{x}_{1}{ }^{2}\right)$ $\left[\mathrm{y}_{1}{ }^{2}\left(\mathrm{x}_{1}{ }^{1}+\mathrm{x}_{\mathrm{B}}\right)-\mathrm{y}_{1}{ }^{1}\left(\mathrm{x}_{1}{ }^{2}+\mathrm{x}_{\mathrm{B}}\right)\right] \geq 0$. The conditions $\mathrm{x}_{1}{ }^{1} \geq \mathrm{x}_{1}{ }^{2}$ and $\mathrm{y}_{1}{ }^{1} \leq \mathrm{y}_{1}{ }^{2}$ indicate that the carrier can invest fewer resources in competition if it decides to invest more resources in cooperation $\left(\mathrm{x}_{1}{ }^{1} \geq \mathrm{x}_{1}{ }^{2}\right.$ and $\left.\mathrm{y}_{1}{ }^{1} \leq \mathrm{y}_{1}{ }^{2}\right)$. On the other hand, the carrier can invest more resources in competition if it decides to invest fewer resources in cooperation $\left(\mathrm{x}_{1}{ }^{1} \leq \mathrm{x}_{1}{ }^{2}\right.$ and $\left.\mathrm{y}_{1}{ }^{1} \geq \mathrm{y}_{1}{ }^{2}\right)$. The second itions are typically satisfied for a carrier with a fixed quantity of resources.

Based on this result, we show that the profit (objective) function for a carrier is concave. Given the linear form of the constraints, we can conclude that the profit maximization program for a carrier is concave. According to Kinderlehrer and Stampacchia (1980), because the profit function is concave, the marginal profit function(the gradient) is monotonic. Therefore, we can state the existence and uniqueness of the coopetition game based on this property. .

\section{Appendix II: The Equilibrium Condition for a Three-Carriers Coopetition Game}

Similarly, we first assume that the total demand of three freight carriers depends on the level of cooperation in the two-stage game.

$$
\mathrm{q}\left(\mathrm{y}_{1}, \mathrm{y}_{2}, \mathrm{y}_{3}\right)=\mathfrak{D}+\mathrm{y}_{1}+\mathrm{y}_{2}+\mathrm{y}_{2}
$$

For readability, we replaced $\mathrm{q}\left(\mathrm{y}_{1}, \mathrm{y}_{2}, \mathrm{y}_{3}\right), \mathrm{c}\left(\mathrm{y}_{1}, \mathrm{y}_{2}, \mathrm{y}_{3}\right)$ and $\mathrm{p}(\mathrm{q})$ with $\mathrm{Q}, \mathrm{C}$ and $\mathrm{P}$ so that the derivation process is clearer. The utility/profit functions of carrier 1,2 and 3 are:

$$
\begin{aligned}
& \pi_{1}=(\mathrm{P}-\mathrm{C}) \mathrm{Qs}_{1}-\mathrm{k}_{\mathrm{x}} \mathrm{x}_{1}-\mathrm{k}_{\mathrm{y}} \mathrm{y}_{1}{ }^{2} \\
& \pi_{2}=(\mathrm{P}-\mathrm{C}) \mathrm{Qs}_{2}-\mathrm{k}_{\mathrm{x}} \mathrm{x}_{2}-\mathrm{k}_{\mathrm{y}} \mathrm{y}_{2}{ }^{2} \\
& \pi_{3}=(\mathrm{P}-\mathrm{C}) \mathrm{Qs}_{3}-\mathrm{k}_{\mathrm{x}} \mathrm{x}_{3}-\mathrm{k}_{\mathrm{y}} \mathrm{y}_{3}{ }^{2}
\end{aligned}
$$


To make the model reasonable, without loss of generality, the following constraints should be imposed:

$$
\begin{gathered}
P \geq C \geq 0 \\
x_{1} \geq 0, x_{2} \geq 0, x_{3} \geq 0 \\
y_{1} \geq 0, y_{2} \geq 0, y_{3} \geq 0
\end{gathered}
$$

The first-order conditions with respect to $\mathrm{x}_{\mathrm{i}}$ required to obtain the corresponding maximum utilities are:

$$
\begin{aligned}
& \frac{\partial \pi_{1}}{\partial x_{1}}=\frac{Q(P-C)\left(x_{2}+x_{3}\right)}{\left(x_{1}+x_{2}+x_{3}\right)^{2}}-k_{x}=0 \\
& \frac{\partial \pi_{2}}{\partial x_{2}}=\frac{Q(P-C)\left(x_{1}+x_{3}\right)}{\left(x_{1}+x_{2}+x_{3}\right)^{2}}-k_{x}=0 \\
& \frac{\partial \pi_{3}}{\partial x_{3}}=\frac{Q(P-C)\left(x_{1}+x_{2}\right)}{\left(x_{1}+x_{2}+x_{3}\right)^{2}}-k_{x}=0
\end{aligned}
$$

The cost of expanding the competitive effort for each carrier therefore are:

$$
\mathrm{k}_{\mathrm{x}} \mathrm{x}_{1}^{*}=\mathrm{k}_{\mathrm{x}} \mathrm{x}_{2}^{*}=\mathrm{k}_{\mathrm{x}} \mathrm{x}_{3}^{*}=\frac{2 \mathrm{Q}(\mathrm{P}-\mathrm{C})}{9}
$$

We can conclude that the equilibrium competitive effort levels are:

$$
\mathrm{x}_{1}^{*}=\mathrm{x}_{2}^{*}=\mathrm{x}_{3}^{*}=\frac{2 \mathrm{Q}(\mathrm{P}-\mathrm{C})}{9}
$$

We next use backward induction to analyze the first stage of the game from the results of second stage. Plugging $\mathrm{x}_{1}{ }^{*}, \mathrm{x}_{2}{ }^{*}$ and $\mathrm{x}_{3}{ }^{*}$ into the carriers' utility functions leads to:

$$
\begin{aligned}
& \pi_{1}=\frac{\mathrm{Q}(\mathrm{P}-\mathrm{C})}{9}-\mathrm{k}_{\mathrm{y}} \mathrm{y}_{1}^{2} \\
& \pi_{2}=\frac{\mathrm{Q}(\mathrm{P}-\mathrm{C})}{9}-\mathrm{k}_{\mathrm{y}} \mathrm{y}_{2}^{2} \\
& \pi_{3}=\frac{\mathrm{Q}(\mathrm{P}-\mathrm{C})}{9}-\mathrm{k}_{\mathrm{y}} \mathrm{y}_{3}^{2}
\end{aligned}
$$

Applying the condition that $\partial \pi_{\mathrm{i}} / \partial \mathrm{y}_{\mathrm{i}}=0, \forall \mathrm{i} \in\{1,2,3\}$, the equilibrium cooperative effort levels are:

$$
\mathrm{y}_{1}^{*}=\mathrm{y}_{2}^{*}=\mathrm{y}_{3}^{*}=\frac{\mathrm{P}\left(1+\frac{1}{\mathrm{~s}_{\mathrm{d}}}\right)-\mathrm{C}\left(1+\frac{1}{\mathrm{~s}_{\mathrm{c}}}\right)}{18 \mathrm{k}_{\mathrm{y}}}
$$

To summarize the results and replace the notations with the original meanings, we list the following equilibrium conditions for this coopetition game:

$$
\begin{gathered}
\mathrm{x}_{1}^{*}=\mathrm{x}_{2}^{*}=\mathrm{x}_{3}^{*}=\frac{2 \mathrm{q}\left(\mathrm{y}_{1}, \mathrm{y}_{2}, \mathrm{y}_{3}\right)\left\{\mathrm{p}(\mathrm{q})-\mathrm{c}\left(\mathrm{y}_{1}, \mathrm{y}_{2}, \mathrm{y}_{3}\right)\right\}}{9 \mathrm{k}_{\mathrm{x}}} \\
\mathrm{y}_{1}^{*}=\mathrm{y}_{2}^{*}=\mathrm{y}_{3}^{*}=\frac{\mathrm{p}(\mathrm{q})\left(1+\frac{1}{\mathrm{~s}_{\mathrm{c}}}\right)-\mathrm{c}\left(\mathrm{y}_{1}, \mathrm{y}_{2}, \mathrm{y}_{3}\right)\left(1+\frac{1}{\mathrm{~s}_{\mathrm{c}}}\right)}{18 \mathrm{k}_{\mathrm{y}}}
\end{gathered}
$$

It can be noted that the equilibrium condition is similar to the condition with two carriers with only minor difference. For the games with more than three carriers, the same process can be applied.

\section{REFERENCES}

1. Agarwal, R. and Ergun, Ö. (2008) Mechanism design for a multicommodity flow game in service network alliances. Operational Research Letters. Vol. 36, pp. 520-524.

2. Agarwal, R., Ergun, Ö. and Sokol, J. (2010) Network design and allocation mechanism for carrier alliances in liner shipping. Under revision for Operations Research. Available at: http://www2.isye.gatech.edu/ oergun/publications/ ErgunPaper5Alliance_OR.pdf.

3. Bengtsson, M. and Kock, S. (2000), "Coopetition" in business networks-to cooperate and compete Simultaneously, Industrial Marketing Management, Vol. 29, Issue5, pp. 411-426.

4. Cachon, G.P. and Netessine, S. (2004) Game theory in supply chain analysis. In: Simchi-Levi D, Wu SD, Shen ZM (eds) Handbook of quantitative supply chain analysis: modeling in the e-business era. Springer Science, New York

5. Dafermos, S. (1983) An iterative scheme for variational inequalities. Mathematical Programming, 26, pp. 40-47.

6. Ergun, Ö., Kuyzu, G. and Savelsburgh, M. (2007) Shipper collaboration. Computers and Operation Research. Vol. 34, pp. 1551-1560.

7. Houghtalen, L., Ergun, Ö. and Sokol, J. (2010) Designing mechanisms for the management of carrier alliances. Submitted to Management Science. Available at: http://www2.isye.gatech. edu/ oergun/publications/AirAlliance_MS.pdf.

8. Humphreys, B.K. (1994) The implications of international code sharing, Journal of Air Transport Management, Vol. 1, No. 4, pp. 195-207.

9. Kinderlehrer, D. and Stampacchia, G. (1980) An introduction to variational inequalities and their applications. Academic, New York

10.Lin, C.-C. and Hsieh, C.-C. (2012) A cooperative coalitional game in duopolistic supply-chain competition, Networks and Spatial Economics, 12, pp. 129-146.

11.Luo, Y. (2007) A coopetition perspective of global competition, Journal of World Business, vol. 42, pp. 129-144.

12.McCain, R. A. (2010), Game theory: A nontechnical introduction to the analysis of strategy, World Scientific, Ohio.

13.Nagarajan, M. and Sosic, G. (2008) Game-theoretic analysis of cooperation among supply chain agents: Review and extensions, European Journal of Operational Research, Vol. 187, Issue 3, pp. 719-745.

14.Ngo, D. D. and Okura, M. (2008), Coopetition in a mixed duopoly market, Economic Bulletin, Vol. 12, Issue20, pp. 1-9.

15.Özener, O. Ö. and Ergun, Ö. (2008) Allocating costs in a collaborative transportation procurement network. Transportation Science. Vol. 42, pp. 146-165.

16.Sutton, J. (1986) Non-cooperative bargaining theory: an introduction, The Review of Economic Studies, Vol. 53, No. 5, pp. 709-724.

17.Tai, H.-H. and Lin, D.-Y. (2012) Carbon reduction and environmental implications of daily-frequency operation in maritime international shipping, Technical Report, National Cheng Kung University.

\section{CONTACT WITH THE AUTHORS}

Dung-Ying Lin*, Ph.D., Associate Professor Chien-Chih Huang, B. Sc.

Department of Transportation and Communication Management Science

National Cheng Kung University

No. 1 University Road, Tainan City, 70101, Taiwan

Phone: +886-6-2757575 ext. 53226

Fax: +886-6-275882

E-mail:dylin@mail.ncku.edu.tw

${ }^{*}$ Corresponding author 